\title{
WERE PORTOLAN CHARTS AND PORTOLANI MADE UPON AUTHENTIC LATE MEDIEVAL MARITIME MEASUREMENTS? EXAMPLE FOR THE ADRIATIC SEA BASIN AREA
}

\author{
Tome Marelić ${ }^{\mathrm{a}}$ \\ ${ }^{a}$ University of Zadar, Department of Geography, tmarelic@unizd,hr
}

Keywords: Portolan charts, Portolani, Cartometric analysis, Adriatic Sea

\begin{abstract}
:
Portolan charts, the oldest preserved (manuscript) nautical charts, were made in the Mediterranean area during the late Medieval and Early Modern Ages, which, in terms of preserved samples' accuracy, appeared in their almost fully developed form. In parallel with them, the portolani; the textual records that primarily contain distance and bearing data between certain coastal features like ports, islands or promontories, and are precursors of modern rutters, were also produced.
\end{abstract}

It is logical to assume that certain, not only functional, but also a causal connection might had existed between the navigation and these two navigational aids, although they represent a different type of media in terms of spatial data storage and display. The most commonly accepted hypothesis is that the portolan charts and the textual data contained in portolani represent an authentic product of the aggregation of a large number of distance and bearing measurements carried out prior to the production of the preserved samples, thus owing their existence to contemporary (Late Medieval) sailors in terms of data gathering, and to contemporary cartographers and portolani-writers in terms of collecting and compiling it. However, the results of this research, which are presented and explained in more detail in author's PhD thesis ${ }^{1}$, do not support that idea. The results suggest that there might be a possibility that cause-and-effect relationships of initial creation of portolan charts (and portolani texts to some extent) maybe rest on some alternative and yet unknown genesis of their origin which should be further scientifically investigated. Some of the results of this research support ideas presented by Scott Allan Loomer ${ }^{2}$, and some support those presented by Roel Nicolai ${ }^{3}$. Both researchers performed extensive cartometric studies and concluded that portolan charts show highest accuracy compared to modern map projected in (modern) Mercator projection. Nicolai went several steps further and demonstrated in detail that it is highly unlikely that portolan charts could be genuine Late Medieval cartographic product.

The cartometric analysis of the data contained in these two types of media is based on a sample of 12 portolan charts (9 made in a smaller and 3 in a larger map scale) and 5 portolani, made from the early 13th to the late 16th century. The research results showed that the geometry of the Adriatic Sea basin coastline renderings on the portolan charts is the most accurate when it is compared to the modern map in the Mercator projection. The results also showed that the portolan charts' accuracy had not been increased during three centuries, even in cases of the map scale enlargement on the later charts. Instead of becoming more accurate, the charts only became geometrically more similar to each other. It implies that newer charts are most likely the copies of older chart (or older charts), rather than genuine works based on their own (independently or semi-independently acquired) spatial data. During three centuries of sample charts' production, a decline of eastern magnetic declination for the Adriatic Sea area had occurred, according to paleomagnetic model CALS3k. $4^{4}$ applied in this research. However, it seems that that phenomenon was not followed by the re-adjustment of the counter clockwise rotation of the Adriatic Sea renderings specific to portolan charts, meaning that later charts were bearing-accuracy wise less accurate than the older ones (if the direction of contemporary magnetic north is used as a line of reference). The research results also showed that the bearings between the endpoints of crossbasin lines (along which it is impossible to sight one endpoint from another) are more accurate compared to bearings between endpoints positioned along the same coast and more than twice closer to each other (where endpoints can be sighted from one another). For the purposes of this analysis, a digital terrain viewshed model was constructed in order to simulate the visual perspective of a sailor on board ship, incrementally divided in dependence of ships' distance from the shore. Textual data on distances and bearings, extracted from portolani, were plotted over selected modern reference maps and over portolan charts (which were previously already georeferenced on a reference map). The results of this analysis showed that portolani data and portolan charts are of similiar accuracy when compared to geometry of a reference map. It was also found out that metrics of sailing routes contained in selcted portolani are geometry wise more similar to their renderings on portolan charts than to their renderings on a reference map. It implies that portolani 
records were not created by aggregating authentic maritime distance and bearing measurements, but that they were more likely extracted directly from (back then already existing) portolan charts.

\section{REFERENCES:}

1 MARELIĆ, T. (2020): Točnost prikaza Jadranskog mora na portulanskim kartama [The Accuracy of Adriatic Sea Renderings on Portolan Charts], PhD thesis, University of Zadar, Zadar

2 LOOMER, S. A. (1987): A Cartometric Analysis of Portolan Charts: a Search for Methodology, PhD thesis, The University of Wisconsin, Madison

3 NICOLAI, R. (2014): A Critical Review of the Hypothesis of a Medieval Origin for Portolan Charts, PhD thesis, Universiteit Utrecht, Utrecht

4 KORTE, M. and CONSTABLE, C. (2011): Improving geomagnetic field reconstructions for 0-3 ka, Physics of the Earth and Planetary Interiors, 188, 247-259 